\title{
Discurso de Agradecimiento del Profesor Dr. Alberto Rodríguez Torres, al Nombramiento como Maestro de la Anatomía de Chile.
}

\begin{abstract}
Sean mis primeras palabras de agradecimiento y reconocimiento por el hecho de estar en esta ceremonia y en este tradicional recinto que ha sido testigo de mi inicio como estudiante de Medicina, luego desempeñándome como ayudante-alumno y posteriormente académico de la disciplina anatómica en la Facultad de Medicina de la Universidad de Chile.
\end{abstract}

Mis agradecimientos a Dios por haberme dado el ser, el entendimiento y la salud; a mis padres por el amor, ejemplo de conducta y sacrificio personal que me permitieron una educación de excelencia y un apoyo y estímulo constante. A mis familiares más íntimos por la comprensión demostrada en relación a mi quehacer anatómico.

Mis recuerdos a quienes me acogieron y encaminaron en la senda de la Anatomía: Al Profesor Adolfo Escobar Pacheco, quien en Abril de 1954 me nombró como ayudante-alumno y me asignó confiadamente la función de prosector. Al Profesor Gustavo Jirón Latapiat, quien en Abril de 1959 y ya con el título de médico, me incorporaba tras concurso de antecedentes, a su grupo de docentes de su Cátedra de Anatomía.

Al profesor Abraham Wainstein Sabat, con el cual trabé amistad muy posteriormente y con el que, junto con el Profesor Humberto Guiraldes, y después de muchas reuniones y gestiones, consolidamos la fundación de la Sociedad Chilena de Anatomía en 1979.

Los tres profesores mencionados, de prolífera trayectoria morfológica, al igual que el Profesos Henckel de Histología de la Universidad de Concepción, me han precedido como Maestros de la Anatomía Chilena.

Mis reconocimientos a la Sociedad Chilena de Anatomía, especialmente a su Directorio, por la distinción concedida y a todos los aquí presentes por acompañarme en tan magnífico acto.

Se le atribuye a Churchill el haber dicho que "las condecoraciones y los honores nunca deben buscarse, nunca deben rechazarse y nunca deben mostrarse". A esto agrego un pensamiento de San Josemaría Escrivá "Cuando percibas los aplausos del triunfo, que suenen también en tus oídos las risas que provocaste con tus fracasos". Recojo, medito y aplico ambas sentencias: acepto este honor no buscado, con humildad y confiado que todo puede ir en beneficio de la causa anatómica.

Mi inicio en Anatomía fue en una época en que trabajar en la Universidad y participar en un grupo como el de Anatomía era un honor muy apetecido:se concursaba los cargos y se hacía mérito, a veces por extensos períodos ad-honorem para poder postular. La mayoría de los docentes tenían un buen pasar clínico,especialmente quirúrgico, y no buscaban la investigación sino la docencia que era adecuada dada la experiencia práctica que poseían.

Existía desde 1938 la Sociedad de Anatomía Normal y Patológica a la que se aspiraba a pertenecer, pero como su nombre lo indicaba, no era homogénea y llevaba el sino de la desaparición,la que ocurrió en 1971 después de una prolongada agonía.

Dos centros morfológicos destacaban: las Universidades de Chile y Concepción. La Pontificia Universidad Católica de Chile formaba sus cuadros docentes; aparecían las filiales regionales de la Universidad de Chile que posteriormente se transformaron (1981)en universidades regionales destacando Antofagasta, Valparaíso y Temuco, ésta como Universidad de la Frontera. En el intertanto se había fundado la Universidad Austral y en la Región Metropolitana la Universidad de Chile ya constaba con cuatro sedes, siendo la última en crearse la Occidente en 1972.

Era un período en que el académico o docente de Morfología, especialmente el de Anatomía Macroscópica, era respetado en su quehacer y su opinión era tomada en cuenta. Era el tiempo de la enseñanza tradicional en la carrera de Medicina y la Morfología no constituía la excepción. Lentamente se fue perdiendo estas características:los cultores muy apegados a estos esquemas, comienzan a escasear y a ser sobrepasados por otras disciplinas más pujantes y renovadoras. Se comienza a producir una brecha generacional, la generación de relevo no se hace presente, se va perdiendo el interés por la disciplina morfológica, hay dispersión de recursos, entre ellos el humano; desaparecen paulatinamente las cabezas conductoras por fallecimiento o retiro y se precipitan situaciones que no se preveían ni en las mentes más negativistas.

La situación coincide con la sentencia lapidaria pronunciada por un morfólogo norteamericano-Kenesi-en 1984 en el seno de la Asociación Americana de Anatomía en relación a lo que sucedía en su país: "La Anatomía tuvo un pasado noble, un presente calamitoso y un futuro precario". A lo anterior puede asimilarse lo escrito por Andreas Vesalio en 1543 en el Prefacio de Humani Corporis Fabrica: 'La filosofía natural (la Anatomía) abarca la descripción del hombre y con razón ha de ser tenida como el más firme fundamento de todo el arte médico y como su principio constitutivo; por eso Hipócrates y Platón le dieron tanta importancia, que no dudaron en asignarle prioridad entre las disciplinas médicas. Y de hecho aunque primero fue cultivada únicamente por médicos y éstos se esforzaron por dominarla, ella comenzó a colapsarse miserablemente cuando los médicos relegaron el "oficio de las manos"a otros y así perdieron la "Anatomía". En efecto,mientras los médicos declaraban que sólo les atañía la curación de las afec- 
ciones internas y consideraban que les bastaba de sobra el conocimiento de las vísceras, descuidaron el de la estructura de los huesos, músculos, nervios, venas y arterias, porque según ellos, no les concernía".

¿Es que estábamos volviendo a la Edad Media y tendríamos como docentes de la Morfología al lector de un libro galénico que lo repetía sin entenderlo y sin conocer otra fuente de información; que no disecaba el cuerpo humano y menos era capaz de hacer una demostración de lo que no había hecho ni conocido?.

Afortunadamente no era todo oscuridad y hubo grupos, pequeños sí, que mantenían la llama de esta ciencia y permitieron conservar el cultivo de la misma. Son hitos de lo señalado:

La creación de la Sociedad Chilena de Anatomía en 1979 la que ha permitido la realización de los que inicialmente fueron los Encuentros anuales, que posteriormente pasaron a ser los Congresos Nacionales y actualmente están entronizados con los del Cono Sur. En 1987 y en Santiago, se llevó a efecto el VIII Congreso Panamericano de Anatomía.

La Sociedad Chilena de Anatomía es miembro de la Federación Mundial de Asociaciones de Anatomía.

Los Anales de Anatomía Normal creados en 1983 y con edición anual, pasaron a ser en 1990 la Revista Chilena de Anatomía con tres fascículos anuales y desde el año 2003 se denomina International Journal of Morphology con cuatro fascículos anuales y que con excelente categoría, sirve también de medio de publicación a la Asociación Panamericana de Anatomía y a la Sociedad Argentina de Anatomía.

Se mantiene excelentes relaciones e intercambio con otras asociaciones y sociedades de Anatomía de diversos países, especialmente con Brazil. Esto permitió desde 1983, la formación en la Escuela Paulista de Medicina de magisteres y doctores chilenos en Anatomía, debiendo reconocer nuestra deuda de gratitud con el Profesor José Carlos Prates, médico de profesión y eximio anatomista, miembro honorario de nuestra Sociedad y principal ejecutor de este intercambio. En la actualidad en nuestro país hay dos Universidades que tienen reconocidos y evaluados Programas de Magister en Morfología.

He citado a la Sociedad de Anatomía como la entidad que ha participado activamente en la preservación y fomento de la Morfología nacional. A ella la ha correspondido velar por la ética de la enseñanza de la especialidad y la dignidad de los docentes tan amenazadas en el presente por la aparición de distintas Facultades (Medicina-Odontología-Medicina Veterinaria) y Carreras vinculadas al área de la salud en Universidades estatales y privadas que sin recursos de personal idóneo ni la implementación de planta física, ni equipos ni material, buscan maximizar el número de alumnos para aprovechar elevados ingresos y obtener pingües beneficios económicos ante la pasividad de los Colegios Profesionales y la oficina para la educación superior dependiente del Ministerio de Educación que debieran controlar realmente lo que se realiza y cómo se realiza esta enseñanza.
Creo que también a nuestra Sociedad Chilena de Anatomía le corresponde encabezar y desarrollar una campaña que a nivel nacional, procure crear en las personas una conciencia y actitud positivas en la donación de cuerpos para la docencia e investigación.

Igualmente estimo que nuestra Sociedad debe tender a promover cursos de Educación Continuada en Morfología-Períodos de Estadía (pasantías), Diplomados, Jornadas de Actualización a nivel nacional y regional, aprovechando las capacidades de grupos organizados que puedan realizarlos garantizando un nivel de calidad reconocido: "Unidos en la diversidad"pudiese ser un lema que se esgrima para estos efectos.

Las Universidades que cuenten con medios adecuados para la formación de personal profesional docente deberían ofrecer la posibilidad de que otras que no pueden formarlos, puedan comprar servicio para este fin. Los docentes no se improvisan ni se sacan de la manga de los magos; se debe tender a la profesionalización del morfólogo: un cirujano no tiene que ser obligatoriamente docente de Anatomía Macroscópica, ni un anátomo-patólogo per se debe ser un buen histólogo, ni un especialista en reproducción es un embriólogo, ni un neurólogo o neurocirujano es necesariamente un neuroanatomista. Con esta profesionalización se evitaría la improvisación de docentes que emergen todos los días y que remedan bastante cercanamente a lo que insinuaba Andreas Vesalius en el siglo XVI

Sin esta profesionalización no habrá tampoco investigación y se tendrá docentes repetidores, deambulando entre Universidades, haciendo un remedo de docencia morfológica que podrá impresionar a alumnos recién egresados de la enseñanza media,pero que a él, fuera de una remuneración económica que puede ser relativamente adecuada, le va dejando cada vez más un vacío de conocimientos, y ninguna posibilidad de actualización.

Queda mucho por hacer.La Sociedad Chilena de Anatomía puede ser el nudo de convergencia y el motor en centralizar proposiciones, y llevar a cabo planes como los enunciados que de realizarse, no trepido en preveer resultados auspiciosos en ética,en inteligencia crítica,en posibilidad de cambios, en responsabilidad social. ¡El futuro está en vuestras manos!

Termino diciendo a la manera de Neruda:Muchas veces, muchas gracias.

\section{Discurso efectuado el día 23 de Octubre de 2004 durante la Jornada Anatómica realiza- das en la Universidad de Chile.}

